\title{
Under-Graduate Academic Programme Self-Evaluation Contained in Higher Education Context: A Defense from South Africa University
}

\author{
Jacob M Selesho \\ Faculty of Management Sciences \\ Vaal University Technology, Vanderbijlpark. South Africa \\ E-mail:jmselesho@gmail.com
}

\section{Doi:10.5901/mjss.2013.v4n14p45}

\begin{abstract}
Recently institutional self-evaluation has become an important management tool implemeted by universities in improving the quality of academic programmes. Compared to earlier decades, not only employers are demanding quality from universities but the goverment is also putting pressure for accountability and improvement. This study is monitoring the use of selfevaluation as a management tool to improve the quality of teaching and learning at undegraduate level. The study did use the documental analyses as data gathering instrument from the two schools selected in a university. The findings revealed that the two case study schools have a mixed quality management porcess with regard to Teaching and Learning approach. The findings did provide the study with an alignment of teaching and learning together with assessment. The study did reveal that quality assessment can only be achieved once quality teaching and learning has taken place. There were a number of lesson learnt in the study for instances linking of teaching, learning and assessment was an eye opener since this takes the quality of teaching and its efficiency and its effectiveness.
\end{abstract}

Keywords: Institutional self-evaluation, teaching and learning, assessment, undergraduate

\section{Introduction}

The quality and quantity of students that are graduating in the South African Higher Institutions (SAHE) have been a concern in the labour market in recent years particular. There have been a number of issues raised by the potential employers with regard to the readiness of the graduate. As a result of these concerns the Department of Higher Education (DoHeT) has revised the funding formula from input funding to throughput funding. The revised funding formula was necessary particular in enhancing the quality of teaching at Higher Education Institutions (HEl's). Although there have been various discussions around the funding formula and its impacts on quality of teaching, there has never been any decisive position taken on how to build the culture of teaching and learning at a number of universities, in some instance the process is at the infancy stage. However, a system of teaching and learning improvement using selfevaluation was initiated by the Council on Higher Education. Therefore, the role of Institutional accountability and quality improvement to a large extent influences the manner in which Quality Assurance (QA) is perceived in SAHE (CHE 2007). In ensuring that the QA matter in SAHE is well taken CHE did establish a permanent committee (i.e. HEQC) with a clear key focus; its main key focus was to concentrate on the three pillars. These pillars include institutional audits, programme reviews and capacity development.

In satisfying the intent of the current study the following question were asked:

Does the university prepare graduates that are ready for the labour market with a particular focus on the quality of teaching and learning afforded to the under-graduates students? In trying to ensure that institutions prepare graduates that are fit for the purpose, the researcher intends to investigate under-graduate academic programme self-evaluation which is important in the SAHE context (CHE 2007).

\section{Theoretical Rationale}

Worldwide, including in SAHE, quality teaching and learning remain an area of interest and concern. In view of this concern some countries have establishment QA structures and practices of self-evaluation for HEl's. The newly established European Higher Education Area (EHEA) was formed after Bologna process to reinforce the importance of quality of academic programme (Bologna 2005). It is in this regard that the strategic goal of EHEA was to implement a 
coherent structure comprises of different component, offering a wide range of quality process and systems. It has been a common practice that when the QA is aimed at implementing a coherent process and systems, the first aspect is internal self-evaluation. Even, thought EHEA is pushing for cooperation and coherent approach, there is also an element of competition, although this competition process is trying to push more on the belief for economic growth at the expense of institutional cooperation (ENQA 2005). This can be viewed in considering the massification in HE as well as the role of $\mathrm{HE}$ in creating a working society. The introduction of Bologna process with the Lisbon strategy has clearly demonstrated the importance of QA by means of putting a particular attention to the growth of the social status. In this particular phenomenon the visible component will be manner in which HEl contribute to the labour force of the nation.

The literature review focused on the conceptualisation of academic programme self-evaluation within a $\mathrm{HE}$ context. Finally, the best practices and lessons learnt of teaching and learning, assessment and the management thereof, were discussed.

\subsection{Conceptualisation of academic programme self-evaluation}

Self-evaluation (SE) may be undertaken at various levels within an institution (i.e. at departmental, school, faculty or institutional level). It is also important to conduct SE before external evaluations or reviews can take place that selfevaluation must have been undertaken (Augusti 2007). Most if not all universities can heavily rely on internal selfevaluation for the purpose of improving its quality process being teaching or reserach; HEI can organised its quality framework in such a way that the system can still perform its designated task even without external reviews (Boele 2007).

Literature have confirmed that if self-evaluation is used appropriately it tend to give an insight of strong points and weak points of a programme or institutional process and procedures, and consequently give a practitioner a good start for the formulation of implementation plans for improvement purposes. Once the institution has taken a decision to undertake self-evaluation the next process is to decide on the operational process (ENQA 2005).

The operational process may limit self-evaluation within the institution as we have either internal or external review. Mammen (2003) argues, that self-evaluation and self-assessment in the university's activities, need to focus on the most important purposes of a university; teaching, learning and assessment of students' performance. Tejedor and Garci-Valcarcel (2007), agree with Mammen's ideas by contending that self-evaluation is a mechanism that certifies whether or not the university has achieved its educational objectives. It is this regard that a well focused self-evaluation will give the institution some highlight on the improvement of quality through self-evaluation procedures. While Malicet (1997) concur with the two authors, he mentions that it is important to identify areas to be reviewed in the self-evaluation process, in most cases the piecemeal process would be followed rather than focusing on the whole process.

\section{Research Methodology}

In order for the researcher to address the research question (see 1) document analysis was used as the most appropriate design. The reason for this was that more in-depth understanding could be obtained as the process is less reactive than any other interactive strategies where the researcher extracts evidence. McMillan and Schumacher (2010:361) confirmed this when they defined document analysis as "a non-interactive strategy for obtaining qualitative data with little or no reciprocity between the researcher and the participant". In this study the self-evaluation report "serve as an immediate practical purpose" by providing detailed accounts of events that unfolded during the interviews that were held with the academics (McMillan \& Schumacher 2010:426). Therefore this study's document analysis denotes the analysis of official documents in the form of self-evaluation reports (2009 \& 2010) of two selected schools, namely the School of Interior Design and the School of Chemical Engineering.

\subsection{Paradigmatic perspective}

The study followed an interpretivist paradigm due to the qualitative approach. The interpetivist paradigm focuses mainly on the individual and set out to understand their interpretation of various systems of their findings. The information gathered from the reports was used to formulate the meaning data generated by the research (see table $1.1 \& 1.2$ ). This main interpretive approach involved attempts to comprehend how institutions academics "construct meaning and explain their worlds" via academic programme self-evaluation (Terre Blanche, Durrheim \& Painter 2006). 


\subsection{Mode of research}

In this study a qualitative mode of research was employed, because it is best suited to encourages the researcher to understand the context. This context refer particularlyto the criteria for teaching, learning, assessment and management of undergraduate academic programmes during self-evaluation.

\subsection{Data collection techniques}

Data was collected in the form of internal self-evaluation reports of two selected schools as mentioned above. Informed consent for data collection were obtained from the Heads of Department (HOD's) of the two selected schools through the quality assurance office.

\subsection{Data analysis and reporting}

The qualitative data obtained from the internal self-evaluation reports were organised, analysed and presented according to three main themes (i.e. teaching and learning, assessment as well as the management thereof. Then researcher constructed categories for analysis by applying the HEQC criteria for self-evaluation for these above-mentioned three themes. These criteria guided the study in assessing its main focus and where these chuncks or group of data were assembled to make a coherent whole (Cohen, Manion \& Morrison 2010).

\subsection{The study population and sample}

The study was conducted at a university in South Africa as the unit of analysis. According to Brynard and Hanekom (2006:55) "the population of the study refers to a group in the universe which possesses specific characteristics". The population of this study consists of all academic Heads of Department (HoDs) from the two Faculties.

In this study a purposeful convenience sampling technique was applied in selecting the appropriate sample. According to Cohen, Manion and Morrison (2007), convience sampling is described as a process where the researcher select a particular group, in part or whole, at the convience of the researcher. For the purposes of this study, the purposesful convenient sample consisted of two selected HODs, as they have participatedand being the key driversin the previous programme reviews, and therefore gained knowledge, skills and experience of self-evaluation at undegraduate level.

\section{Findings and Discussion}

The preceding section did provide an outline of the research design and methodology employed in this paper. The current section focuses on the report of the documents analyses (e.g. institutional internal self-evaluation reports of two selected schools and related findings as compiled by the reviewers). For the purpose of this study, the focus were on Teaching and Learning. In this way the main objective (see 1.4) of this study was realised, namely to:

Does the university prepare graduates that are ready for the labour market with a particular focus on the quality of teaching and learning afforded to the under-graduates students?

The section below will discussed the SE and audit reports of two schools and finally the individual school reports (see table 1.1 \& 1.2). It was importnat to use the two reports as both schools were intended to improve the quality of academic programme. The self-evaluation report was the self reflection approach by the schools, while the audit or reviewers report was based on the panel findings. Therefore, in conducting an authentic study one need the two reports as they were compiled from the same information but for different purposes. The self-evaluation was prepared by the academic staff for improvement purpose, while the reviewers was actually being very judgemental on the quality of teaching and leraning of the academic offerings.

The paragraph below will discussed the two reports from the schools followed by the reviewers reports and finally the reseracher comments. 


\subsection{Report on the nalysis of the self-evaluation and reviewers comments}

In light of the volume of the self-evaluation- and audit reports, it was imperative that self-evaluation per individual school be separately analysed (see 1.1 and table 1.2). The section below will dealt with the two schools reports detailing the focus of the study which is teaching and learning.

\subsubsection{School of Interion Design and School of Chemical Engineering}

Table 1.1: Documental Analysis reports of School of Interion Design

\begin{tabular}{|c|c|}
\hline Self-evaluation & Reviewers Comments \\
\hline $\begin{array}{l}\text { Teaching and Learning: Teaching and Learning strategy Criterion } 5 \\
\text { To facilitate teaching and learning process and optimize the student } \\
\text { realisation of his/her potential, learning guides were developed in an } \\
\text { outcomes-based education approach. The following aspects are } \\
\text { reflected in each learning guide: } \\
\text { - Curriculum alignment } \\
\text { - } \quad \text { Course content } \\
\text { - } \quad \text { Learning programme per learning unit } \\
\text { - Assessment methods and criteria } \\
\text { Teaching and learning is supported by the institutional teaching plan } \\
\text { and other institutional policies, such as the teaching and learning policy, } \\
\text { assessment policy as well quality assurance policy. The following unit } \\
\text { plays a pivotal role: } \\
\text { - Teaching and learning unit } \\
\text { - Curriculum development unit } \\
\text { Workshops are conducted regularly to support the academic staff. } \\
\text { Students' performance is monitored on a regular basis by lecturers so } \\
\text { as to identify the underperformance. The university follow the process of } \\
\text { identfying all risky students through continous assessment and from the } \\
\text { admission process as the requirements. In addition to that the university } \\
\text { is using yearly assessment with the method of writting both in June and } \\
\text { November and both marks are combined. In this case it is easy to }\end{array}$ & $\begin{array}{l}\text { Teaching and Learning: Teaching and Learning } \\
\text { strategy Criterion } 5 \\
\text { The programme is supported by the faculty and } \\
\text { university quality assurance systems. Staff development } \\
\text { and improvement of teaching and learning take place } \\
\text { regularly. The programme enables students to develop } \\
\text { foundational competencies in the course. However, a } \\
\text { review of study guides suggests that there is little } \\
\text { opportunity for students to relate theory to practice as a } \\
\text { basis for changing and developing practice. Students } \\
\text { indicated that in most modules they were not given } \\
\text { activities that would have enabled them to apply their } \\
\text { knowledge and understanding of language practice } \\
\text { theory and principles to real or simulated contexts. } \\
\text { It was recommended that the unit should: } \\
\text { The unit should develop procedures for } \\
\text { regular monitoring and evaluation of } \\
\text { teaching and learning interactions. } \\
\text { Students should be given real or simulated } \\
\text { activities that enable them to apply their } \\
\text { knowledge and understanding of language } \\
\text { practice theory and principles. }\end{array}$ \\
\hline
\end{tabular}

Table 1.2: Documental Analysis reports of School of Chemical Engineering

\begin{tabular}{|c|c|}
\hline Self-evaluation & Reviewers Comments \\
\hline $\begin{array}{l}\text { Teaching and learning: Teaching and Learning strategy Criterion } 5 \\
\text { The institutional Teaching and Learning plan informs all stakeholders what the } \\
\text { university does in the area of teaching and learning as well as future plans. All the } \\
\text { teaching and learning plans of the various Schools and Programmes in the } \\
\text { Faculty are in line with the institutional plan. } \\
\text { Since } 2001 \text { the method of teaching has to a greater extent become student- } \\
\text { centered and the School has moved towards the implementation of various } \\
\text { sources within the learning process, including interactive group work and the use } \\
\text { of alternative sources such as the Internet. Since } 2002 \text { the School of Chemical } \\
\text { Engineering has been actively participated in the teaching and learning project of } \\
\text { the university. Staff of the School of Chemical Engineering was regularly exposed } \\
\text { to the concept of outcome based education (OBE) by means of brief information } \\
\text { sessions in order to facilitate the later implementation of OBE in the School. Thus } \\
\text { since } 2002 \text { Outcomes-based Education as an underlying paradigm to teaching }\end{array}$ & $\begin{array}{l}\text { Teaching and Learning: Teaching and } \\
\text { Learning strategy Criterion } 5 \\
\text { A review of all available documentary } \\
\text { evidence indicates that students are } \\
\text { provided with guidance on how the } \\
\text { different components of the programme } \\
\text { contribute to the learning outcomes of the } \\
\text { programme. Assessment criteria are } \\
\text { clearly communicated to students on } \\
\text { commencement of their studies. Lecturers } \\
\text { are trained to develop learning materials. } \\
\text { Some staff members are involved on } \\
\text { national level in the re-curriculation } \\
\text { process of the Certificate to become a } \\
\text { Bachelor's degree. }\end{array}$ \\
\hline
\end{tabular}




\begin{tabular}{|c|c|}
\hline $\begin{array}{l}\text { A growing number of modules in the School of Chemical Engineering are } \\
\text { presented by means of electronic learning (e-learning). It is foreseen that the } \\
\text { electronic format of learning at all levels level will be extended. } \\
\text { Learning facilitation includes the following: } \\
\text {-Formal Classes } \\
\text {-Self-Learning activities } \\
\text { - Peer-and self assessment } \\
\text {-Practical demonstrations } \\
\text {-Group work } \\
\text { Practical work is integrated with theory in all relevant instructional offerings. Work } \\
\text { integrated learning (WIL) forms an integral part of teaching and learning in the } \\
\text { school and employers that assist in WIL must be accredited by the HPCSA in }\end{array}$ & $\begin{array}{l}\text { Details regarding contact sessions appear } \\
\text { on the official time table. All the other } \\
\text { information needed by students to enable } \\
\text { them to know what is expected from them } \\
\text { as far as teaching and learning is } \\
\text { concerned, appear in the calendar. } \\
\text { A clear indication is given to students on } \\
\text { how the different components of the } \\
\text { programme contribute to the learning } \\
\text { outcomes of the programme. Learning } \\
\text { material is aligned with the programme } \\
\text { goals and underpinning philosophy, and } \\
\text { are suitable with respect to content, level, } \\
\text { purpose, and linkage of assessment } \\
\text { strategies to specific learning outcomes. }\end{array}$ \\
\hline
\end{tabular}

The above-mentioned information highlights the key points coming from the self-evaluation reports as well as the reviewers reports. It is clear that the two schools have indeed appointed academics with adequate academic qualifications and relevant experiencing to lead and manage the academic units. It is on the basis of the information provided on table 1.1 and 1.2 that the researcher could realise that the university has some guidelines with regard to the teaching and learning plan that should be followed by the different schools, however it was not clear whether there are any mechanism in place to ensure that this teaching and learning plan is applied accordingly across all specrtum. Finally, while university have policies that regulate and govern teaching and learning, it was unfortunate its implementation were not clear with regard students, progress drop out and risks just to mention few. Full discussion of this tables will now be discussed.

\subsection{Discussions and analysis of the documents}

Every step in programme reviews starts with programme SE which is guided by internal process. In most cases the SE process is prepared and ultimately evaluated according to the agreed set of criteria as prescibed by the HEQC. It is an evidence based led kind of self-evaluation where the institution assess itself against the set criteria. In the case of the current study the reserach was focusing only on the identified criteria. From table 1.1 and 1.2 only teaching and learning criteria were looked and verified by means of assessing both the self-evaluation reports and reviewers comments. This criteria was applied according to what they claim in the self-evaluation report as prepared by the institution (see table 1.2).

\subsubsection{Process of Self-evaluation}

From table 1.1 and 1.2 it can be clearly stated that self-evaluation is a highly contested terrain, there are competing voices between the schools and the external reviewers. From the external reviwers it is clear that they see things with the different lenses as compared to the self-evaluation reports. For example table 1.2 number on assessment, the reviewers comments are clear that although the institutions have various policies with regard to assessments, it is still not clear on how this policies and practices are used in improving the curriculum deliversies.

Table 1.3 its main intent is to outline the comments of the reseracher as drwan from the evidence of both table 1.1 and 1.2 . 
Table 1.3: HEQC criteria and comments on present and suggested quality practice descriptors. These comments were drawn by comparing the self-evaluation report and the reviewers comments

\begin{tabular}{|c|c|}
\hline HEQC Criteria & Comments on present and suggested quality practice descriptors \\
\hline $\begin{array}{l}\text { Teaching and } \\
\text { Learning: } \\
\text { Teaching and } \\
\text { Learning strategy } \\
\text { Criterion } 5\end{array}$ & $\begin{array}{l}\text { The reports indicate a close relationship between programme design on the one hand and the quality of } \\
\text { teaching and learning. A critical aspect of this is the capacity of the university to manage teaching and } \\
\text { learning and develop fully integrated programmes. Non alignment of units with programmatic aims was } \\
\text { attributed, in various, to a lack of management or the lack of integrated policy on teaching and learning. The } \\
\text { teaching and learning strategies can be commended in this particular programme. It is clear that the } \\
\text { institutional teaching and learning plan has been clearly cascaded down to the programme level. There is a } \\
\text { commitment from the lecturer to enhance teaching and learning in this programme. Some programmes were } \\
\text { offered at a more conventional three part-model. In most cases there is a predominance of academic } \\
\text { modules(see Table 1.2). } \\
\text { QA within HE takes place throughout the teaching and learning process. It includes screening of candidates } \\
\text { for admission, staff recruitment and promotion procedures, curriculum reviews, teaching and learning } \\
\text { facilities, quality of research, policy development and management mechanisms, student evaluation of staff, } \\
\text { external examiners for end-of-semester or end-of-year examinations, tracer studies, academic reviews and } \\
\text { audits. Though little information is available in the internal reviews reports on the effectiveness of these } \\
\text { methods, anecdotal information collected during this study indicates that implementation of some of these } \\
\text { processes is weak due to financial constraints, failure to keep up with new approaches to teaching and } \\
\text { learning, and increased workload resulting from large student numbers (see Table 1.2). }\end{array}$ \\
\hline
\end{tabular}

It is clear from the reports as stated in table 1.3 that there are conflicting views regard the intrpretation of both the selfevaluation and reviewers commnets flwoing from the self-evalaution report.

The researcher will attempt to intreptate the data obtained in order to formualte meanings.

\section{Analysis and Interpretation of Data Obtained from Documental Analysis}

The faculties which houses two schools represent just one means by which the university have developed and adopted counteracting mechanisms of its own by which to address issues of quality is to a large degree being observed to be uneven. This can be confirm by looking at table 1.1 and 1.2 in comparing the self evaluation and reviewers reports with regard to teaching and learning. In the case of the two schools it was not clear which framework or oganisational approach were followed by the university in assessing quality of teaching and learning. It was clear that every school had a different approach on how quality of teaching and learning should be assessed and more importantly the interptretation of teaching and learning criteria (see table 1.1 and 1.2).

It is clear that the two schools were following the programme acreditation guidelines, this was regarded as standard practise to assess institutional SE. This SE was used by the external reviewers to assess the authenticity of the schools reports and readiness with regard to quality of academic offerings. In moving forward the very self-evaluation reports could be used in future external reviews as a process by the school in reviewing its internal QA matter. It could be interesting to follow whether the issues that need improvement were followed and ultimately met all of them.

Three valuable lessons arise from this study example. First, it is important that QA be part of the institution's strategic plan, the top structure of the institution must draw a strategies and operational aspect of those plans. Such plans should be developed through an all-inclusive consultative process in order to ensure broad ownership.

\subsection{Quest for SE}

As elsewhere in the world, the quest for quality has always been a priority in HE in South Africa. Until recently, the tension between political pressure to expand access and the desire by academics in HEls to maintain quality did not allow a healthy culture of quality to evolve. Changes in QA mechanisms over the years were driven by factors such as rapid enrollment growth to meet increasing social demand, significantly decreased public funding of HE amid rising enrollment, and the effects of the brain drain. However, recent increases in private sector participation in tertiary education appears to have provided the trigger for governments, and to a less extent institutions, employers and the public, to give a greater attention to educational quality 


\subsection{A quality philosohy and culture through SE}

Another academic put this statement to test "it is important that the faculty must develop a self-evaluation framework that will guide quality process in a uniform way. If the proposed self-evaluation framework can be approved that will be the first step in ensuring that QA culture is encouraged in the Faculty that encourage the improvement element. This will be a good buy-in approach for most, if not all academics. He further mentioned that the idea to use the self-evaluation as an improvement tool is good but from the data it was clear that academics had overrated their programme to a large extent, and that they become disappointed with the outcomes of the re-accreditations.

\section{Conclusions}

The findings revealed that the two case study schools have a mixed quality management approach with regard to Teaching and Learning approach. The findings did provide the findings from the reports as analysed (e.g. institutional internal self-evaluation reports of two schools and related findings as compiled by the reviewers). The focus of the study was SE of Teaching and Learning. In this way the study wanted to align itself with the objective (1.4) of this study. There were a number of lesson learnt in the study. The criteria were also looked and more importantly the study reveal that these criteria guide the programme in developing a coherent programme. The linking of teaching, learning and assessment was an eye opener since this takes the quality of teaching and its efficiency and its effectiveness.

Although the criteria were clearly spell out on how the minimum requirement should focus on. It was at this juncture that the researcher felt that the SE matters is not well cascaded at the academic programmes, furthermore it was quite difficulty for HOD's to manage these units by aligning themselves with a particular alignment of SE. Finally, a conclusion will be made emanating from the discussion of the study.

\subsection{Teaching, Learning and Assessment}

Finally, the educational effectiveness of the students learning depends on sound self-evaluation. From this exercise it is important that SE should be driven internally using the institutional process to enforce the culture of SE through different teaching, learning, assessment and managment guidelines. It is also important that the SE process should not only be a compliance process but rather an internal improvement process based on continous process.

This study did establishes that the assessment and teaching have a different roles to play in the curriculum process. It is for this reason that the following aspects were observed for instance teaching suitability according to the university requirements and the learning content aligned with the outcomes sfrom the content is also importnat. It is important that the universuity uses the above mentioned process to observe the process.

\section{Recommendations}

All ISE should thus reflect the crucial relationship between self-evaluation and planning (i.e. institutional, departmental strategic, functional or operational planning).

ISE is also used to determine reputational ratings according to available resources, learner outcomes and talent development and becomes enhanced by the added value. The predominant aspects, namely those pertaining to teaching at undergraduate and postgraduate level and research, are to be found in the true mission of Higher Education institutions. However, "there is a tension between the degree of access and the achievement of quality. Adequate financial, human and physical resources will have to compete with the demands of many other pressing needs in the future. The tension can only be met if the system can be developed in such a way and is flexible enough to allow reasonable access in proportion to the resources available.

Academics in this study where compelled to comply with the external evaluation system of the HEQC, while it was not clear on the internal process to be followed in achieving the external compliances, their means towards complying was to a certain extent dramatic. Critique is too central to the academics endeavour to passively accept quality mechanisms in which they have little faith. 


\section{References}

Augusti, G. 2007. Accreditation of engineering programmes: European perspective and challenges in a global context. European Journal of Engineering Education 32(2):273-283.

Boele, E.B. 2007. Handbook on Internal Quality Assurance for Conservations. Utrecht, AEC Publication.

Bologna Process 2005. A framework for qualifications of the European higher education area. Accessed on 2010 December.

Bless, C.; Higson-Smith C. \& Kagee. A. 2007. Fundamental of Social Research Methods an African Perspective. Cape Town: Juta and Company.

Brynard, P.A \& Hanekom, S.X 2006. Introduction to Research in Management related field. Pretoria: Van Schaik Publishers.

Cohen, L.; Manion, L. \& Morrison, K. 2007. Research Methods in Education. London:Routledge Falmer Publishers.

CHE (Council on Higher Education) 2004a. South Africa Higher Education in the First Decade of Democracy. Pretoria: CHE.

CHE (Council on Higher Education) 2007. A case for improving teaching and learning in South Africa Higher Education. Pretoria: CHE.

ENQA 2005. Standard and guidelines for quality assurance in the European Higher Education. Belgium.

Harvey, L. \& Stensaker, B. 2006. Quality culture: understanding, boundaries and linkages. Paper presented at 29th EAIR Forum, Innsbruk, Austria, 26-29 August.

Huusko, M. \& Ursin, J. 2010. Why (not) asses? Viwes from the academic department of Finnish Universities. Assessment \& Evaluation in Higher Education. 35(7):859-869.

Malicet, DP 1997. Evaluation and self-evaluation in the French Universities. European Journal of Education 32(2):165-174.

Mammen, K.J. (2003). A study of quality dimensions in the faculty of science of a selected university. D.Ed Theses. Umtata: Walter Sisulu University

McMillan, J.H. \& Schumacher, S. 2010. Research in Education. New York: Pearson Education, United States of America.

Tejedor, F. and Garcia Valcarcel, A. 2007. In Revista de Educacion. (342): 443-448).

Terre Blanche, M., Durrheim, K. \& Painter, D. 2006. Research in Practice: Applied methods for social sciences. Cape Town: University of Cape Town Press. 